Cipango
Cipango

$21 \mid 2014$

Nouveaux regards sur les arts de la scène japonais II

\title{
Eddy DUFOURMONT, Histoire politique du Japon de 1853 à
} 2011

Presses universitaires de Bordeaux, 2012, 459 p.

\section{Guibourg Delamotte}

\section{(2) OpenEdition}

Journals

Édition électronique

URL : https://journals.openedition.org/cipango/2360

DOI : $10.4000 /$ cipango.2360

ISSN : 2260-7706

Éditeur

INALCO

Édition imprimée

Date de publication : 31 décembre 2014

ISSN : 1164-5857

Référence électronique

Guibourg Delamotte, «Eddy dufourmont, Histoire politique du Japon de 1853 à 2017 », Cipango [En ligne], 21 | 2014, mis en ligne le 26 septembre 2016, consulté le 30 juin 2021. URL : http:// journals.openedition.org/cipango/2360 ; DOI : https://doi.org/10.4000/cipango.2360

\section{(c) $(1)(9)$}

Cipango est mis à disposition selon les termes de la Licence Creative Commons Attribution - Pas d'Utilisation Commerciale 4.0 International. 


\section{Dufourmont Eddy, Histoire politique du Japon de 1853 à 2011, Presses universitaires de Bordeaux, 2012, 459 p.}

L'Histoire politique du Japon de 1853 à 2011 par Eddy Dufourmont, maître de conférences à l'université Michel de Montaigne de Bordeaux, retrace l'histoire du Japon depuis son ouverture forcée et la fin du Bakufu, à nos jours. On peut considérer cet ouvrage comme la première histoire politique du Japon publiée en France. Peu d'Histoires du Japon contemporain - celles de Francis Abbad (1993), de Jean-Marie Bouissou (1997), de Jacques Gravereau (1993), de Michel Vié (1995), etc. - avaient été écrites, et aucune ne portait sur la totalité de cette période, ce qui empêchait de l'appréhender dans sa logique d'ensemble; aucune n'était récente. On peut par conséquent estimer que l'auteur comble un vide en abordant du début à la fin - si l'on peut dire - cette histoire marquée par un essor extraordinaire et fragile, par une consternante dérive, enfin par un rétablissement et un succès éblouissants.

Eddy Dufourmont aurait pu adopter un angle d'analyse, s'intéresser à un problème particulier : $s$ 'interroger par exemple sur le rôle de l'étranger dans la politique japonaise, sur l'influence des lobbys industriels dans la politique étrangère du Japon, sur la relation entre pouvoir civil et militaire pendant et après la guerre, sur la nature particulière du fascisme japonais, sur la place du peuple dans cette histoire, ou encore suivre l'un des fils continus de cette dernière : la figure impériale, mi-spectatrice, mi-actrice. Cela aurait été négliger trop d'éléments, qu'il présente comme imbriqués les uns dans les autres. Il laisse à d'autres ou à des travaux ultérieurs ces approches ciblées. D'emblée, il prévient qu'il n'a d'autre ambition que de retracer le parcours du Japon durant plus de cent cinquante ans. La fresque apparaît dans son ensemble : il recense les évènements en les exposant selon un découpage chronologique inhabituel et original, et en s'appuyant largement, pour les expliquer, sur des sources primaires ou secondaires japonaises. 
Et il le fait avec une rare précision. Chaque chercheur, chaque étudiant, chaque lecteur trouvera ce qu'il recherche dans cet ouvrage. Ainsi, qui s'intéresse à l'apparition de la démocratie au Japon verra dans ces pages les premières associations politiques défendre des intérêts de plus en plus généraux et les partis prendre davantage de place dans l'arène politique, avant d'accéder enfin au gouvernement. Puis, de l'écrasement d'émeutes au début du siècle jusqu'au sabordage des partis au début des années 1940, on voit la démocratie s'éteindre durant la guerre sans complètement s'évaporer malgré la censure, le contrôle de la pensée et des comportements exercés via les écoles et les associations de voisinage, malgré la propagande dont les instruments seront les médias et l'éducation. On voit cette démocratie, à peine installée, encore mal à l'aise dans ses habits et dans ses meubles, où les pratiques l'emportent sur les textes, où les doctrines sont encore à l'essai, sacrifiées à un intérêt national mal compris et dicté par l'armée ; l'asservissement volontaire (pour paraphraser La Boétie) des pouvoirs et contre-pouvoirs qui se fondent dans l'« union nationale ». La montée en puissance de l'armée et son émancipation croissante du pouvoir civil, et même de l'empereur, la manière dont elle parvient à user de la Constitution pour imposer au gouvernement un rapport de force qui lui soit favorable, annoncent les débordements et crimes à venir. Enfin, la démocratie renaît sous l'impulsion de l'occupant américain, dont Eddy Dufourmont évoque aussi les avancées, les difficultés et les revirements. Le parti libéral-démocrate, qui gouverne presque sans interruption entre 1955 et 2009 et revient au pouvoir en décembre 2012, soulève d'autres questions en termes de démocratie, de par sa capacité à rester au pouvoir.

Autre fil conducteur suggéré par le livre, celui de la relation entre politiques intérieure et étrangère : de la guerre civile de Boshin, dont l'arrière-plan est l'ouverture aux étrangers et les traités inégaux qui l'instaurent, aux guerres par lesquelles le Japon se frotte au monde - d'abord contre la Chine en 1894-1895 puis contre la Russie en 1904-1905 - on assiste à l'élévation du Japon au rang de puissance ; et l'on est témoin des frustrations qu'il conçoit, les États-Unis, le Royaume-Uni et la France rechignant à lui faire place, et des difficultés qui en résultent pour les gouvernements japonais successifs.

Le thème de la construction nationale offrirait une autre grille de lecture, tout aussi intéressante, du livre et de la période : on comprend en effet comment l'unification nationale est favorisée par les conseillers de l'empereur ; comment à la 
faveur de la scolarisation, de la conscription, de l'industrialisation, la population se fait nation ; comment en unifiant le territoire et la société par la disparition des seigneuries locales, la remise des domaines, la disparition de la caste des samourais et de leur droit à porter le sabre, les oligarques de l'époque stabilisent le pouvoir de l'empereur au sommet d'un nouvel édifice, celui du Japon moderne.

Le thème de la puissance est également présent : à l'ère Meiji, le Japon s'aligne sur le modèle qu'offrent les Occidentaux et opte pour la colonisation qui lui assure par ailleurs la perspective de ressources naturelles et énergétiques, ainsi que de l'espace dont il manque - la poussée démographique consécutive à l'amélioration de l'hygiène et des connaissances médicales entraînant une surpopulation. L'attrait de la puissance explique que les militaires soient peu sanctionnés des crimes qu'ils commettent au Japon au début des années 1930 et des coups de force qu'ils fomentent en Chine, où ils échappent à tout contrôle. Après la guerre, on assiste à un formidable effort de réintégration à la communauté internationale.

Tout ou presque se trouve dans ce livre qui s'apparente à une chronique de l'histoire politique de la période, à la fois le fruit d'une patiente et rigoureuse recherche, et un précieux instrument de travail. 
